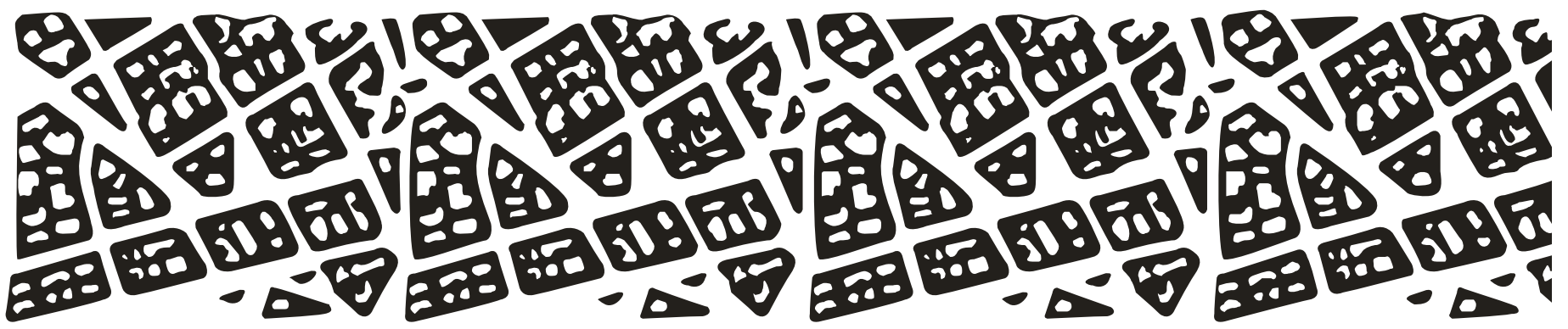

\title{
Implicações da ilusão modernizadora em Cidade de Deus
}

\section{Wendell de Freitas Amaral}

\section{Deus mesmo, quando vier, que venha armado! E bala é um pedacinbozinho de metal...}

(João Guimarães Rosa)

\section{Resumo}

Pretende-se verificar neste trabalho as relações entre a ineficácia dos projetos modernizadores no Brasil e suas consequências no contexto social narrado no romance Cidade de Deus, de Paulo Lins.

Palavras-chave: Cidade de Deus; romance; criminalidade; Paulo Lins.

\section{Abstract}

This work intends to check the relations between the powerlessness of modernist projects in Brazil and its consequences on the social context related on the novel Cidade de Deus, wrote by Paulo Lins.

Keywords: Cidade de Deus; novel; criminality; Paulo Lins.

O romance Cidade de Deus, de Paulo Lins (1997), conhecido mundialmente graças à adaptação para o cinema (2002), tornou-se foco de discussões e objeto de diversas pesquisas em diferentes áreas do conhecimento, devido à sua estreita ligação com a realidade social das populações faveladas do Rio de Janeiro. A perspectiva com que aborda as relações de convivência e conflito entre 
os moradores da favela, na década de 60 , e os desdobramentos até a transformação em neofavela, na década de 80 , é o ponto central que fez do romance um paradigma de estudo. A ambiguidade que se estabelece na relação entre a população de Cidade de Deus com a criminalidade, que constitui um poder paralelo às instituições legais, talvez tenha sido o que mais atraiu a atenção na receptividade da obra.

Outro aspecto importante é o modo como é narrado o romance, diferente de outras narrativas sobre a marginalidade que abordavam a miséria de um ponto de vista externo. Em Cidade de Deus ${ }^{1}$, percebe-se uma empatia e um profundo conhecimento desta realidade social pelo narrador onisciente, revelando a consciência do próprio marginal acerca de sua condição de excluído. Por esse motivo, a ótica da ascensão social atingida através dos assaltos e do comércio de drogas, passa além da simples dicotomia entre bem e mal. Vista por esse ângulo, a relação entre estes desvalidos e a sociedade de consumo que está à sua volta é uma relação conflitante, pois há a cobrança originada do que falta e a inserção compulsória destes pobres numa esfera social da qual foram alijados no processo de modernização.

Essa análise da obra explora o violento crescimento do desejo de consumo dos desprivilegiados em meio à miséria, fratura existente entre a sociedade moderna/industrializada e o condomínio popular que está à margem das políticas democratizantes. Portanto, essa abordagem parte do ponto de vista de que houve uma falência dos projetos modernizadores que visavam atingir uma coesão social no país.

\section{Três momentos até Cidade de Deus.}

Esses excluídos e miseráveis da sociedade brasileira, e as peculiaridades do seu modo de vida, foram pincelados de modo pitoresco nas páginas de nossa literatura nos romances do século XIX. Passaram a ser mais recorrentes na Belle-Époque, em contos e crônicas urbanas como as de João do Rio e Lima Barreto. Mas é nos anos 30, com o chamado romance regionalista, que a temática da miséria é marcante, retratando, sobretudo, a pobreza do nordestino e sua migração para os grandes centros. É neste período de nossa história, da proclamação da República ao projeto industrialista, que se acende o pavio para a grande explosão de miséria urbana, que deriva dos anseios progressistas para a modernização do país.

Esse processo urbanizador e excludente é iniciado no Rio de Janeiro com a "regeneração" promovida pelo prefeito Pereira Passos, no início do século, e que tinha como objetivo coletivo fundamental a consagração do progresso baseada na remodelação da cidade. Com a reestruturação da área central da capital houve a expulsão das classes populares para os subúrbios e para cima dos morros que a circundavam. Essa medida visava à eliminação de quaisquer grupos marginais das áreas centrais que seriam praticamente isoladas para o desfrute exclusivo das camadas aburguesadas (SEVCENKO, 1989, p.30).

O resultado dessa exclusão pode ser observado na crônica "Os livres acampa-

1 Todas as citações referentes à obra são da $2^{\mathrm{a}}$ edição, revista pelo autor e publicada em 2002; indicadas no corpo do texto somente as páginas. 
mentos da miséria" (RIO, 2006, p.131-140), de 1911, na qual João do Rio visita o morro de Santo Antônio e revela as condições precárias de moradia, como a falta de iluminação das casas feitas de caixão de madeira sobre a terra batida das encostas escarpadas. $\mathrm{O}$ cronista acaba admirado por ver como vivem aqueles miseráveis que conseguiram a "construção inédita de um acampamento de indolência, livre de todas as leis" e muito próximo da Avenida Central, o maior símbolo arquitetônico da recente modernização.

Antonio Candido (1986, p.140-162) afirma que, a partir do decênio de 30, irá prevalecer na literatura nacional a consciência de subdesenvolvimento, em contraposição a uma visão de "país novo", de uma grandeza ainda não realizada, muito marcante nos decênios anteriores. Para o crítico, esta consciência permanece até a década de 80 e é baseada no distanciamento entre o Brasil e os países ricos, destacando a pobreza e a atrofia; o que falta, não o que sobra. A partir do decênio de 30 passa a ser crescente na ficção uma visão desmistificadora do homem rústico. O que levava a uma interpretação deste homem, entregue aos níveis mínimos de sobrevivência, como um ser diminuído e reduzido às suas funções elementares, simbolizadas pelo balbucio linguístico dos personagens de Vidas Secas.

Nos anos 60, após o surto desenvolvimentista e o otimismo da década anterior, a mobilização destas populações para os grandes centros atinge um grau irreversível e incontrolável. A nova ideologia urbanista buscava atingir um equilíbrio social com a promessa de um universo de cidadania, com trabalho assalariado garantido em uma atividade econômica moderna. Porém, esse processo que desagregava à distância o velho enquadramento rural, provocava a inserção dos pobres nas cidades, onde ficavam largados à disposição das novas formas de exploração econômica e de manipulação populista. A cultura tradicional não desaparecera, mas passara a fazer parte de um processo de outra natureza. Presente no ambiente moderno configurava um desajuste extravagante (SCHWARZ, 1999, p.155-162).

Após o golpe de 64, a ideologia desenvolvimentista é retomada, mas sob os interesses militares de transformar o país em potência. A questão dos marginalizados era entendida, principalmente, como um problema de estrutura habitacional. Houve um avanço nas políticas públicas para que esses miseráveis que se localizavam em favelas fossem removidos para moradias adequadas de baixo custo, medida paliativa semelhante à de Pereira Passos na "regeneração", o que parecia aos governos garantir a incorporação desta população à sociedade moderna (ZALUAR, 1985, p.64).

Assim é descrito no romance de Paulo Lins o início da ocupação de Cidade de Deus, aglomerado de pessoas de diferentes favelas, junto aos desabrigados pelas enchentes de 1966:

Por dia, durante uma semana, chegavam de trinta a cinquenta mudanças, do pessoal que trazia no rosto e nos móveis as marcas das enchentes. Estiveram alojados no estádio de futebol Mário Filho e vinham em caminhões estaduais cantando:

Cidade Maravilhosa

cheia de encantos mil... (p.17)

\section{Realismo feroz}

É na década de 60, quando o fluxo migratório da miséria caracterizou uma 
mudança estrutural nos grandes centros, que surge uma nova tendência na literatura nacional fazendo do suburbano e do malandro os protagonistas de obras como as de João Antônio e Rubem Fonseca.

Antonio Candido (1986, p.199-215) aponta os dois escritores como precursores de um "ultra-realismo" sem preconceitos, o qual agride o leitor pela violência dos temas e dos recursos técnicos, avançando para uma notícia crua da vida. Iniciado com as visões nada edificantes do homem no regionalismo de 30 , este movimento de desliterarização torna-se maduro com a quebra dos tabus de vocabulário e sintaxe, com o gosto pelos termos considerados baixos (segundo a convenção) e com a desarticulação estrutural da narrativa - heranças estéticas do modernismo de 20. Essa insurreição na linguagem e a recorrente violência urbana são essenciais para a evolução deste tipo de ficção, que Candido denomina realismo feroz.

A primeira mudança se instala no plano da linguagem quando a voz do narrador se funde à voz dos personagens, abolindo a diferença entre o falado e o escrito, tendo como principal marca a gíria. A narrativa em $1^{\mathrm{a}}$ pessoa, que se torna comum depois de Guimarães Rosa, tem grande importância nesse processo de fusão de pontos de vista. Nesse sentido, a crítica de Jesus Antônio Durigan demonstra como João Antônio estabelece uma identidade entre o narrador e o meio narrado, utilizando-se de técnicas vanguardistas:

os "erros sintáticos", os enunciados quebrados, as frases curtas, a sonoridade reproduzindo a linguagem oral, as gírias, os estereótipos, os ditos populares, os dramalhões, as tragédias cotidianas, não devem ser entendidos superficial e preconceituosamente. Constituem partes integrantes de um tipo de criação literária, que se realiza através de um trabalho particular de montagem. (SCHWARZ, 1983, p.218)

Para trazer ao plano da narrativa toda a representatividade histórica e lingüística dos jovens favelados nas três décadas passadas nas páginas de Cidade de Deus, Paulo Lins também faz uso desta bricolagem, baseando-se no estudo antropológico de Alba Zaluar sobre a criminalidade no RJ, com o auxílio de pesquisadoras de história e linguagem. Dessa forma, traz para o processo de composição literária uma técnica anticonvencional muito utilizada no cinema. O que, para Roberto Schwarz, é uma componente das "energias artísticas da atualidade" que amplia a perspectiva da obra: "o mundo relacional armado pelo jogo das posições fica na interseção da lógica do cotidiano, da literatura de imaginação e do esforço organizado de autoconhecimento da sociedade" (SCHWARZ, 1999, p.168).

Numa entrevista concedida ao n. 74 da revista Caros Amigos (2003), Paulo Lins esclarece que escreveu o romance utilizando-se da "colagem" dos elementos da realidade da periferia para compor sua ficção. Ressalta o autor que sua intenção era estritamente literária e não documental, aludindo ao romance-reportagem muito praticado na década de 70. Para ele, "a realidade não cabe na literatura", se fosse contada como é o livro seria "impublicável".

A brutalidade deste fragmento da realidade, porém, não é transmitida pelo foco narrativo na $1^{\text {a }}$ pessoa. Mesmo sendo feito com a mediação da $3^{\text {a }}$, a perspectiva do narrador não parte de fora e não traz os preconceitos de classe que contribuiriam 
negativamente para um realismo forçado e obtuso. O olhar aqui é interno, de quem conviveu e pesquisou sobre as relações humanas de Cidade de Deus. O espaço do livro é focado no conjunto habitacional, tendo seus personagens pouquíssimas incursões fora dali. A linguagem do narrador onisciente, com a constância do discurso indireto livre, é frequentemente contagiada pela de seus jovens personagens, o que parece convertê-la em discurso direto:

Busca-Pé fez questão de apertar o baseado (...) Ele mesmo o acendeu, deu dois catrancos e passou para o parceiro. Em dias de chuva, as horas passam despercebidas para quem está ao léu dará. Busca-Pé mecanicamente verificou a hora, constatou que estava atrasado para a aula de datilografia, mas que se foda, já tinha perdido um montão de aulas, mais uma não ia alterar nada. (p.13)

Ficaria difícil imprimir tanta agilidade e habilidade discursiva numa narrativa longa em $1^{a}$ pessoa, pois ao contrário de um Riobaldo - que fora jagunço alfabetizado e até professor no Grande Sertão: Veredas - em Cidade de Deus, com poucas exceções, o analfabetismo e o pouco interesse pelo estudo é patente. Além disso, como os personagens marcantes são crianças ou adolescentes com um precário conhecimento de mundo, dar-lhes voz narrativa poderia comprometer a ação contínua que se realiza na obra. Se "falha a fala", a narração deve ser mediada.

Outro ponto marcante no realismo feroz, que cria novas necessidades no leitor, é a correspondência com a violência urbana "em todos os níveis do comportamento. Guerrilha, criminalidade solta, superpopulação, migração para as cidades, quebra do ritmo estabelecido de vida, marginalidade econômica e social" (CANDIDO, 1986, p.212). Todos esses aspectos sociais compõem a tensão vivenciada por esses habitantes da favela "onde cada homem é apenas um animal de instintos impulsivos, em que ora se é muito amigo e grande inimigo de um momento para outro" (RIO, 2006, p.136).

No início de Cidade de Deus, o narrador interrompe as brincadeiras dos meninos e adverte o leitor esclarecendo sua intenção enunciativa: "o assunto aqui é o crime, eu vim aqui por isso..." (p.20). A tensão e o perigo que correm as personagens são reproduzidos pelo imediatismo do corte narrativo. Mesclando a linearidade aos flash-backs, o ritmo do livro é sem trégua e precipita-se para soluções sempre fatais. "Essa intimidade com o horror, bem como a necessidade de encará-lo com distância, se possível esclarecida, é uma situação moderna" (SCHWARZ, 1999, p.167).

Nesse processo é possível recortar pequenos contos de horror, como os casos de traição amorosa (um bebê esquartejado; uma mulher enterrada viva no quintal), crimes praticados por personagens anônimos e isolados das relações com a bandidagem e o tráfico, mas que chocam o leitor apresentando-se como únicas soluções possíveis para os fatos, pela naturalidade com que são narrados.

O que se vê até o fim é o desenvolver da violência e da criminalidade para uma chocante e inédita abordagem literária da substituição do tipo social da malandragem de outrora, tão cantada e muitas vezes associada à identidade nacional, por um tipo sanguinário, obcecado pelo poder capitalista. A divisão ternária da obra, que corresponde cronologicamente aos decênios de 60,70 e 80, demonstra esse processo de transfiguração da imagem romantizada do marginal heroico à realista do traficante cruel. 
Na "história de Inferninho" é narrada a criação do bairro e os conflitos que se centralizavam pelas ações do Trio Ternura, liderado por ele. Roubavam por sobrevivência e ainda mantinham uma certa conduta ética com os vizinhos, parentes e amigos, ajudando-os com o fruto de seus assaltos.

Já na "história de Pardalzinho" percebe-se uma modificação na conduta dos malandros que agora não têm mais dificuldades para conseguir armas e dinheiro, pois se inicia a expansão do comércio de drogas na favela. Porém, Pardalzinho ainda respeita certas regras de caráter, opondo-se até mesmo ao seu maior parceiro para manter uma ética nas relações entre os malandros conceituados.

Por fim, na "história de Zé Miúdo" tem-se a nova característica social dos bandidos. Na neofavela, regida pela crueldade bélica do tráfico de drogas, o que se vê são crianças abaixo dos dez anos empunhando armas de grosso calibre e ameaçando toda a população pela necessidade de matar visando exterminar outros grupos. Inho se tornou Zé Miúdo e um dos maiores chefes do crime nas favelas do Rio de Janeiro. O que se verá é um constante revezamento no comando das ações do tráfico, pois nesse contexto basta estar vivo para ser morto.

\section{Falência dos projetos modernizadores}

Cidade de Deus representa um núcleo da sociedade excluída pela falência dos projetos modernizadores iniciados na virada do século. Já na década de 60 , quando nos países desenvolvidos a modernização está concluída, vê-se que grande faixa da população brasileira e da América Latina encontra-se incapacitada para o domínio dos signos culturais modernos. Para Canclini (1990, p.201-237), isso deveu-se a um simulacro da modernidade, uma constituição estatal inconsistente, que representou o desenvolvimento de uma cultura elitista e excludente, levando a uma migração que transtorna as cidades. Para ele, existem quatro movimentos básicos que regulam a modernização e podem ser assim resumidos:

Projeto emancipador: secularização dos campos culturais; racionalização da vida social.

Projeto expansivo: domínio da produção e da ciência, circulação e consumo de bens.

Projeto renovador: renovação e reformulação dos signos de distinção que o consumo massificado desgasta.

Projeto democratizador: confiança na educação, na difusão da arte e dos saberes especializados, para alcançar uma evolução racional e moral.

Se analisarmos a realidade dos personagens do romance de Paulo Lins, veremos que é claro o distanciamento cultural deles em relação aos projetos modernizadores. Isso se torna mais contraditório se pensarmos que a favela, o espaço quase absoluto no romance, está inserida numa metrópole considerada a capital cultural do Brasil. Esse desacordo social causa problemas até para a efetivação da ação criminosa, prejudicada pela incapacidade cognitiva dos bandidos na hora da decisão, como no assalto ao motel:

(Pelé e Pará) Pararam à frente de um quarto e achavam melhor invadir outro. A indecisão atropelava os segundos. Resolveram seguir a ordem numérica. Ler não sabiam, mas contar era mole para eles. Adentraram o 301. (p. 66) 
$\mathrm{O}$ analfabetismo generalizado é a marca mais intensa dessa exclusão. Ele se torna o maior obstáculo para que haja a expansão e a circulação dos bens culturais. Tampouco haverá uma renovação destes signos, pois a dependência cultural impõe a aceitação dos produtos estrangeiros da cultura massificada. Apesar do desejo de consumo, muitos dos personagens estão aquém dos domínios do saber especializado, portanto, não se consolida o projeto de democratização. A educação e a arte são ignoradas ou desprestigiadas pelos poucos que têm acesso a elas, como alguns dos jovens cocotas da classe média. Esse desprestígio da educação, por outro lado, representa o domínio do imaginário popular pelo que Antonio Candido chamou de "folclore urbano", elementos da cultura massificada que impõem "valores duvidosos e bem diferentes dos que 0 homem culto busca na arte e na literatura” (CANDIDO, 1986, p.145):

Batman era um super-herói terráqueo, tinha de torcer por ele. Super-Homem era o mais forte de todos os super-heróis, mas se National Kid quisesse o derrubava mole, pois o raio de sua pistola tinha criptonita e o caralho. Aquele tal de doutor Smith dos Perdidos no espaço é a maior bichona. (...) Meu amigo tem um cachorro ensinado igual ao Rin Tin Tin. (p.82-83)

O absoluto desconhecimento da arte especializada e os avanços pós-mo-dernos alcançados principalmente na literatura e na música passam fora desse contexto. Não se vê em um único momento a apreciação literária por parte dos personagens, nem mesmo aqueles poucos filhos da classe média parecem se interessar. Somente os policiais, também estes sem muita escolaridade, trazem uma ou outra publicação com histórias de bang-bang: "No posto policial, os soldados Jurandy e Marçal dormiam no segundo andar. Na parte de baixo, cabo Coelho lia um livro de bolso: Texas Kid volta para matar" (p.55).

Já com a música, é um pouco diferente, nos bailes haverá uma substituição dos estilos com o passar do tempo. Dos sambas de enredo ao soul, do rock à música eletrônica. Porém, o valor artístico das obras é ignorado pela maioria, como na discussão entre Busca-Pé, apreciador da chamada Música Popular Brasileira, e os cocotas, que tratam com preconceito as mudanças culturais simbolizadas pelo comportamento dos artistas nacionais:

\begin{abstract}
A maioria nunca tinha assistido a um show, teatro nem pensar. Diziam que Caetano e Gil eram viados, Chico Buarque era comunista, Gal e Bethânia, sapatonas. Papo bobo, não tinham sensibilidade para entender as metáforas das canções, não sabiam nem o que era metáfora. Uma vez, lhe disseram que Caetano beijava boca de homem. Imediatamente Busca-Pé respondeu que aquilo era quebra de tabu. Um dos cocotas revidou, na mais pura picardia, afirmando que tabu era pau no cu. (p.150)
\end{abstract}

Há, portanto, uma inversão das expectativas no exemplo citado. O mais pobre (Busca-Pé) parece mais bem informado que os cocotas da classe média, ignorantes da arte. Também nas relações pessoais fica patente o desajuste e a incoerência, numa falsa estabilização social pregada pela propaganda positivista dos governos. Cidade de Deus comporta em seu núcleo humano duas das componentes étnicas mais discriminadas na história do país, que ficam a par dos privilégios de uma burguesia que se diz 
solidária e justa. De um lado os negros e mulatos que sofrem com o preconceito de cor e com o estigma de bandidos. De outro os migrantes das regiões rurais, principalmente do nordeste, que na condição de desterrados pela miséria sofrem com a alcunha de sujeito inferior. Há nesse sentido uma desarmonia entre os próprios desvalidos da democracia, o que invalida outra condição básica para a modernização, segundo Canclini, que é a racionalização da vida social e moral.

No livro de Paulo Lins, essa desarmonia pode ser demonstrada por três situações diferentes envolvendo o ponto de vista de um nordestino e de dois bandidos negros, nos quais o preconceito racial surge como revolta gerada pela ameaça da bandidagem, no primeiro, e a traição amorosa e a penúria econômica, nos outros:

A única coisa ruim do Rio de Janeiro era a presença de crioulos por toda parte. Argumentava com os amigos que o loiro era filho de Deus, o branco Deus criou, o moreno era filho bastardo e preto o Diabo cagou. Ter informado à polícia a casa de Martelo foi sua grande vingança contra os seres daquela raça de picolé de asfalto. (p.52-53)

Imaginava sua mulher escorrendo a língua na cabeça do pau de um branquelo qualquer, arregaçando a buceta para receber um caralho branco, quem sabe até de um paraíba. Ela sempre gostou dos brancos, por isso não desgrudava os olhos da televisão na hora das novelas, onde os negros não apareciam. Quando aquele tal de Francisco Cuoco surgia no televisor, ela quase gozava. (p.68)

$\mathrm{O}$ assaltante não gostava de branco bem-arrumado. Achava que eles tomavam o lugar dos negros em tudo. (...) quando via um branco bem-arrumado, assaltava, cometia violências para vingar o negro que teve seu lugar roubado na sociedade. (p.131)

Numa outra esfera, o imaginário social que não se sustenta com as promessas democratizadoras de uma evolução baseada no conhecimento científico e no domínio das técnicas de produção, mantém a confiança em formas tradicionais de crença espiritual. Como o poder do Estado, representado pelas instituições de educação, saúde pública, segurança e justiça, não abarca suas necessidades, o povo do conjunto se fia nesses métodos, primitivos para uma sociedade moderna. Se um amigo morre, houve magia negra contra ele. Se a polícia não distingue bandido de trabalhador, recorre-se à pombagira para o "fechamento" do corpo. Se o pacto social não existe, pactua-se com o Diabo, pois Deus "fica muito longe".

Portanto, este cenário politicamente desolador, de onde os personagens não conseguem sair e onde trabalhadores assalariados convivem familiarmente com bandidos que esperam "fazer a boa", permanece até o fim do livro, revelando os traços da sociedade contemporânea, na qual grande parte da população se encontra desagregada da modernização concretizada. É possível concluir, como Roberto Schwarz (1999, p.159-160), que esse "processo da modernização, (...) não se completou e provou ser ilusório". Provocando uma situação histórica inédita que transforma todas as aglomerações urbanas de miseráveis em "sujeitos monetários sem dinheiro, ou ex-proletários virtuais, disponíveis para a criminalidade e toda sorte de fanatismos". 


\section{Sujeitos monetários sem dinheiro}

Nas três décadas que correspondem ao fluxo narrativo em Cidade de Deus, a evolução do crime segue paralela aos avanços da prática capitalista, cada vez mais apoiada no consumismo sem limites. Como essa condição é privilégio de uma minoria social, a parte que carece do poder econômico, para usufruir dos confortos básicos, utiliza-se dos meios violentos dos atos criminosos para suportar a falta e atingir um estágio que lhe dê uma dignidade, mesmo que esta seja ilusória, trazendo a morte prematura. Essa massa da população impelida às metrópoles pela urbanização acelerada encontra-se impotente, senão pelo crime, diante da neurose do consumo.

Desejos simples e pueris como ter um autorama e nunca vê-lo realizado, como o de Busca-Pé que, apesar das tentativas não se envolveu com o crime, se revolta ao pensar na situação degradante do pobre:

Era infeliz e não sabia. Resignava-se em seu silêncio com o fato de o rico ir para o exterior tirar onda, enquanto o pobre vai pra vala, pra cadeia, pra puta-que-pariu. (...) Tentou se lembrar das alegrias pueris que morreram, uma a uma, a cada topada que dera na realidade, em cada dia de fome que ficara para trás. (p.12)

Os criminosos utilizam-se de todo tipo de estratégias para conseguir seu sustento diário. Roubando as "cachangas" e "sabargando" motéis e postos de gasolina cultivam a esperança de um dia "fazer a boa", o que significa ganhar muito dinheiro e aproveitar a riqueza. Até o início da guerra do tráfico, poucos são os "bichos soltos" que são ladrões e matadores por puro prazer e desejo sanguinário, quando "as piores desumanidades adquirem sinal positivo uma vez que alcancem sair na mídia, uma espécie de aliada para romper a barreira da exclusão social" (SCHWARZ, 1999, p.165):

Dali a pouco Inferninho entrou com pão, leite e café, e o jornal com a foto dos assassinados no assalto: (...)

- Sabe ler? Sabe ler? - perguntou Inho a Ferroada, ciente de que Inferninho lia mal.

- Não - respondeu enfatizando a resposta com a cabeça.

- Aí, vô lá no Pardalzinho pra ele ler essa parada aí pra gente. (...) Pardalzinho, já na casa de Ferroada, lia a matéria derrapando na entonação das orações mais longas. Mesmo assim Inho ouvia como uma criança que escuta histórias de fadas, sentado no chão e a cabeça recostada no sofá. (p. 163)

Por isso, fica simples captar a perspectiva desses segregados do capitalismo selvagem, sujeitos monetários sem dinheiro, que depois da prática do terror, refletem sobre a necessidade de sair da vida do crime. Muitos deles morrem com a ilusão do paraíso monetário. Os mais velhos mantêm ideais hippies, sonhando "rebentar a boa" e comprar um sítio, fugir para o interior, criar galinha, plantar maconha. Ou imaginam-se, tal qual Inferninho, como o burguês, como os personagens da novela ou os filhos da classe média que se vestem na moda e ostentam poder:

O negócio era chegar à quadra do Salgueiro ou do São Carlos com uma beca invocada, um pisante maneiro, mandar descer 
cerveja pra rapaziada, (...) olhar assim para a preta mais bonita e chamar pra beber um uísque, mandar descer uma porção de batatas fritas, jogar um cigarro de filtro branco na mesa, ficar brincando com a chave do pé-de-borracha para a cabrocha sentir que não vai ficar no sereno esperando condução, comprar um apartamento em Copacabana, comer filha de doutor, ter telefone, televisão, dar um pulinho nos States de vez em quando, que nem o patrão de sua tia. Um dia acharia a boa. (p.42)

Poucos, é verdade, aceitam ser "otários" (ganhar a vida trabalhando que nem escravo para patrão mandar). Como no caso de Martelo, ex-integrante do Trio Ternura, que "virou bíblia" e conseguiu um emprego na construção civil, certo de que essa era a única maneira de viver com a mulher fora da Cidade de Deus. Mesmo aqueles favelados da classe média, os cocotas, que possuíam condições sociais para a ascensão através da educação e de uma capacitação profissional, se rendem à ambição do dinheiro rápido e fácil do crime:

Manguinha balançava a cabeça, dizia que não tinha mais cabeça para estudar, e mesmo se estudasse nunca iria ficar rico do jeito que ele queria, afirmava que seria bandido somente por um tempo. Arrumaria mais uma grana, juntaria com a que já tinha guardada e compraria uma fazenda no mais distante dos interiores do país. (p. 257)

Os policiais, braços de uma instituição falida e corrompida, que têm no paradoxal comércio de armas uma fonte extra de renda, pois as vendem aos bandidos para depois combatê-los, também são vítimas do desejo cada vez mais forte de poder e riqueza, como é perceptível pelas intenções do detetive Belzebu:

Em casa, olhou as panelas, queria comer alguma coisa apetitosa, nada de gostoso havia ali. Apetitoso era o cargo de chefe de polícia. Pensou novamente em comprar um diploma para passar a delegado e depois ser chefe de polícia. Sabia que existia um advogado, doutor Violeta, e um professor, Lauro, que vendiam diplomas: assim que tivesse um tempinho os procuraria. (p.166-167)

Mas a certeza de riqueza só é concretizada com o crescimento do comércio de drogas, quando a classe média vai à neofavela deixar seus pertences em busca da "felicidade". Enquanto a classe média aperta o baseado, os bandidos vão apertando o dedo. Zé Miúdo torna-se o maior traficante de Cidade de Deus após tomar de assalto outras "bocas" concorrentes e passa a legislar e gerenciar o comércio de entorpecentes:

Tinha a certeza de que ficaria rico em pouco tempo e essa certeza era sem dúvida a melhor que já tivera. Compraria logo um carro, uma porrada de casas, tênis da onda, roupa invocada, uma lancha, televisão colorida, telefone, ar-condicionado e ouro, muito ouro para garantir seu bem-estar pelo resto da vida. (p.210)

O comando do tráfico passa a esbanjar dinheiro, dominar os moradores, e enfrentar a polícia com melhores armas, isso provoca o fascínio das crianças pelo poder 
de fogo que possibilita o respeito social e a efetivação do consumismo nunca antes desfrutado por eles. Essa atitude é clara na resposta de Filé com Fritas, de oito anos, ao ser repreendido por Zé Bonito, que quer vê-lo na escola:

- Meu irmão, eu fumo, eu cheiro, desde nenenzim que peço esmola, já limpei vidro de carro, já trabalhei de engraxate, já matei, já roubei... Não sou criança não. Sou sujeito homem! (p.318)

\section{A humanização pela poesia}

Utilizando a mescla de gêneros como as citações de letras de canções populares ou as orações que suplicam nas vozes de um sincretismo de crenças, o modo jornalístico de algumas descrições, os cortes e perspectivas cinematográficas e as acertadas pontadas de ironia e humor-negro, a narrativa proporciona ao leitor uma captação bastante variada do espaço e da psicologia de seus personagens.

Ao iniciar o romance, Paulo Lins demonstra que sua veia lírica também colabora para a construção da obra. "A ousadia da linguagem mais notável (...) vem por conta de uma inesperada insistência na poesia - à qual pode-se objetar muita coisa, menos o grande acerto de sua presença" (SCHWARZ, 1999, p.169):

Poesia, minha tia, ilumine a certeza dos homens e os tons de minhas palavras. É que arrisco a prosa mesmo com balas atravessando os fonemas. É o verbo, aquele que é maior que o seu tamanho, que diz, faz e acontece. Aqui ele cambaleia baleado. Dito por bocas sem dentes nos conchavos de becos, nas decisões de morte. A areia move-se no fundo dos mares. A ausência de sol escurece mesmo as matas. O líquido-morango do sorvete mela as mãos. A palavra nasce no pensamento, desprende-se dos lábios adquirindo alma nos ouvidos, e às vezes essa magia sonora não salta à boca porque é engolida a seco. Massacrada no estômago com arroz e feijão a quase-palavra é defecada ao invés de falada. Falha a fala. Fala a bala. (p. 21)

Em outra parte, à maneira do poema de João Cabral, "O Capibaribe e a leitura”, o rio traz a edição da primeira notícia da guerra entre Zé Miúdo e Zé Bonito. Distantes dos acontecimentos, Busca-Pé e Barbantinho compreendem os fatos numa leitura da morte que "se impõe a quem lhe dá a ler, letra a letra" (MELO NETO, 2002, p.52-53). A vermelhidão que tinge a correnteza e esparrama os cadáveres é de "Sangue diluindose em água podre acompanhado de mais um corpo trajando calça Lee, tênis Adidas e sanguessugas sugando o líquido encarnado e ainda quente." (p.13-14).

Em meio aos crimes, há outros momentos em que o narrador reflete sobre sua própria construção linguística, como depois da morte do malandro Passistinha:

Já dera oito horas quando um grito sustentou no ar a repetição duma só oração:

- Passistinha morreu, Passistinha morreu, Passistinha morreu!!! Deu-se um corte na manhã, oriundo de uma oração de verbo intransitivo e sujeito morto. (p.91) 
Em muitas passagens, há no romance de Paulo Lins uma desumanização, uma espécie de animalização instintiva dos personagens em busca da sobrevivência no espaço dominado pela violência sem limites.

Há, porém, um fator que dá a esses seres sufocados pela miséria uma redenção diante do leitor atônito. $\mathrm{O}$ que recupera o caráter humano dos personagens, principalmente daqueles mais envolvidos com o terror, na tensão extrema das ações do livro é a presença da poesia. Seja no aspecto formal do texto, seja pela condensação sentimental em alguns seres cruéis. É ela que desvenda, através das máscaras mais monstruosas que representam aqueles jovens, boas intenções marcadas pelo afeto, pela amizade e pelas manifestações inesperadas de culpa e perdão, revelando os resquícios de uma inocente infância ainda presente em cada um deles. Exemplo dessas reviravoltas instantâneas é a atitude de Zé Miúdo, que ao render um "teleguiado" da quadrilha de Bonito não o mata, mas pede ao garoto para que cante "Maluco Beleza". O bandido procura em uma estrela a imagem angelical do finado Pardalzinho que o abraça, canta e sorri apontando que o menino deveria ser libertado. Miúdo piscou o olho para o vazio onde enxergara o amigo e seguiu sua recomendação aconselhando o refém:

- Sai dessa vida rapá... Vai embora! Alguém te fez alguma coisa pra entrar na guerra? Vai procurar uma escola! (p.362)

Porém, o que prevalece é o crime.

Apesar da morte da alegria popular e da liberdade desfrutada na bela paisagem carioca, que desaparece em Cidade de Deus, talvez possa ser usada aqui, para resumir seus contrastes, a definição de Cortázar para a manifestação da poesia no romance do século XX, que somada à violência urbana, no campo da elaboração imagética, coopera para a sensação realista e chocante do livro: "O golpe de estado que dá a poesia no próprio território da prosa ficcional (...) revela em toda sua violência magnífica as ambições de nosso tempo e seus lucros" (CORTÁZAR, 2006, p.71-72).

\section{Referências bibliográficas:}

CANCLINI, Néstor García. La modernidad después de la posmodernidad. In: Modernidade: vanguardas artísticas na América Latina. Ana Maria de Moraes Belluzo, organizadora. São Paulo: Memorial: UNESP, 1990.

CANDIDO, Antonio. "Literatura e subdesenvolvimento" e "A nova narrativa". In: A educação pela noite e outros ensaios. São Paulo: Editora Ática, 1986.

CORTÁZAR, Julio. "Situação do romance". In: Valise de Cronópio. São Paulo: Perspectiva, 2006.

DURIGAN, Jesus Antônio. A ciranda da malandragem. In: SCHWARZ, Roberto (org.). Os pobres na literatura brasileira. São Paulo: Brasiliense, 1983.

LINS, Paulo. Cidade de Deus. $2^{\mathrm{a}}$ ed., São Paulo: Cia. das Letras, 2002.

_Entrevista explosiva. Revista Caros amigos. São Paulo: Casa Amarela, $\mathrm{n}^{\circ} 74,2003$.

MELO NETO, João Cabral de. Seletas. Rio de Janeiro: Nova Fronteira, 2002. 
RIO, João do. Vida vertiginosa. São Paulo: Martins Fontes, 2006.

SCHWARZ, Roberto. "Fim de século" e "Cidade de Deus". In: Sequências brasileiras. São Paulo: Cia. das Letras, 1999.

SEVCENKO, Nicolau. Literatura como missão. Tensões sociais e criação cultural na Primeira República. São Paulo: Editora Brasiliense, 1989.

ZALUAR, Alba. A máquina e a revolta. As organizações populares e o significado da pobreza. São Paulo: Brasiliense, 1985. 